\title{
FUZZY MULTIATTRIBUTE CONSUMER CHOICE AMONG HEALTH INSURANCE OPTIONS
}

\author{
Cengiz KAHRAMAN ${ }^{\mathrm{a}}$, Asli SUDER ${ }^{\mathrm{b}}$, Ebru TURANOGLU BEKAR ${ }^{\mathrm{c}}$ \\ Industrial Engineering Department, Istanbul Technical University, \\ Macka Besiktas, 34367 Istanbul, Turkey \\ ${ }^{b}$ Management Engineering Department, Istanbul Technical University, \\ Macka Besiktas, 34367 Istanbul, Turkey \\ 'Department of Industrial Engineering, İzmir University, Üçkuyular, 35350 İzmir, Turkey
}

Received 21 February 2012; accepted 20 January 2013

\begin{abstract}
People buy insurance to protect themselves against possible financial loss in the future. Health insurance provides protection against the possibility of financial loss due to health care use. A selection among health insurance options is a multiattribute decision making problem including many conflicting criteria. This problem can be better solved using the fuzzy set theory since human decision making is generally based on vague and linguistic data. We propose an integrated methodology composed of fuzzy AHP and fuzzy TOPSIS to select the best health insurance option. The considered option types, Health Savings Account (HSA), Flexible Spending Accounts (FSA), and Health Reimbursement Arrangement (HRA) are evaluated using eight different criteria under fuzziness. A sensitivity analysis is also realized.
\end{abstract}

Keywords: health insurance, options, fuzzy sets, AHP, TOPSIS, multiattribute.

JEL Classification: I13, P46.

\section{Introduction}

Health insurance is a type of insurance coverage that pays for medical and surgical expenses those are incurred by the insured. Health insurance can either reimburse the insured for expenses incurred from illness or injury or pay the care provider directly. Health insurance has been an important issue and its applications differ among countries: Australia (Connelly et al. 2010), Africa Countries (Carapinha et al. 2011), Uganda (Basaza et al. 2008), South Korea and Taiwan (Lee et al. 2008), Ireland (Armstrong 2010), Canada (Devlin et al. 2011),

Corresponding author Cengiz Kahraman

E-mail: Kahramanc@itu.edu.tr 
Bulgaria (Atanasova et al. 2011), India (Dror et al. 2007), Holland (Bartholomée, Maarse 2007), China (Wagstaff, Lindelow 2008), Mexico (Gameren 2010), etc.

With competition increasing among health care plans, employees of large firms typically are faced with more opportunities for choice and more complex options than in the past. Most people understand that an insurance choice may be important for them, but their decision making also appears very limited. The dominant model of choice assumes careful examination and weighing of alternatives, but as the number of choices grows, this becomes an increasingly complex and difficult task.

The selection of health plans and providers is, in part, an iterative process in which individuals better learn to make informed choices responsive to their needs. The instability in initial choices, however, suggests considerable failure to understand important differences among plans in access, cost, and freedom to select providers or to be reimbursed for services outside the plan. This is particularly true as populations select plans with which they have had little prior experience. Some preferences seem much more central to people's decisions than others. The primary preferences are related to the character of established doctor/patient relationships, cost, and special needs (Mechanic 1989).

There are numerous different health insurance plans available in any country today. Because every person has their own unique situation, determining "the best" health insurance plan will vary from person to person. Situations vary and health insurance plans that are right for one person's situation may not be right for someone else's. This is why we propose a methodology for the selection among health insurance options in this paper.

Individual choice over health insurance policies may result in risk-based sorting across plans. People are generally unsuccessful in selecting an alternative with more than four criteria. In approaching choice situations, people immediately make efforts to narrow the number of operative choices to a psychologically manageable set. Typically, individuals consider very few alternatives and focus the comparison only on a subset of the many relevant dimensions. People are more likely to select familiar options. Familiarity may be assessed by prior experience with a particular type of health plan arrangement (Mechanic 1989).

The selection among health insurance options is a multiattribute decision making problem with many conflicting criteria like eligibility, portability, catch up contribution, and tax treatment. This problem is difficult to solve since people usually assign linguistic expressions rather than numerical ones. The research question of this paper is how this problem can be solved under vague and linguistic data.

Since human reasoning is vague, these linguistic evaluations involve some degree of uncertainty. The fuzzy sets theory was introduced by Zadeh (1965) to express the linguistic terms in decision making process in order to resolve the vagueness, ambiguity and subjectivity of human judgment. Fuzzy methods are purposely designed for complex and ill defined problems. Hence, many researchers have attempted to use fuzzy MCDM methods like analytic hierarchy process (AHP), analytic network process (ANP), outranking methods, multiple objective linear programming (MOLP) and goal programming.

The aim of this paper is to assess health insurance options considering multiple and conflicting criteria under incomplete and vague information using the fuzzy set theory. To the best knowledge of the authors, this is the first multiattribute fuzzy decision making study in 
the health insurance literature. Two multiattribute methods are used in the evaluation of health insurance options. Since a decision-maker bases judgments on knowledge and experience, then makes decision accordingly, the AHP approach agrees well with the behavior of a decision maker. The strength of this approach is that it organizes tangible and intangible factors in a systematic way, and provides a structured yet relatively simple solution to the decision making problems. TOPSIS is preferred since it includes simple, rationally comprehensible concept, good computational efficiency, and ability to measure the relative performance for each alternative in a simple mathematical form.

To obtain the criteria weights, the most used method in the literature is AHP. The obtained weights are used as an input to TOPSIS method, which needs the criteria weights to be determined by the decision maker. Both methods are handled under fuzziness in our paper.

The rest of the paper is organized as follows. Section 1 gives a literature review on health insurance. Section 2 presents the health insurance options, which are Health Savings Account (HSA), Health Reimbursement Arrangement (HRA), and Flexible Spending Account (FSA). In Section 3, the selection criteria for health insurance options are given. In Section 4, a multiattribute selection using an integrated Fuzzy AHP-TOPSIS methodology is proposed. In the last section an application of the proposed methodology is realized together with a sensitivity analysis.

\section{Literature review on health insurance}

Recent works on health insurance are summarized in the following. These works are usually on risk evaluation and choice of health insurance systems.

Jack (2001) examines the nature of health insurance contracts when insurance companies pool high- and low-risk individuals. In a spatial product differentiation model, the normal forces of competition induce quality provision, but selection incentives induce insurers to under-provide quality. To offset selection incentives, the government can reimburse some of the insurers' costs. Iarossi and Helms (2002) assess group health insurance for fully-insured vs. self-insured employers. Sapelli and Vial (2003) study the existence of self-selection and moral hazard in the Chilean health insurance industry. Dependent workers must purchase health insurance either from one public or several private insurance providers. They analyze the relationship between health care services utilization and the choice of either private or public insurance. In the case of independent workers, they analyze the relationship between utilization and the decision to voluntarily purchase health insurance. The results show selfselection against insurance companies for independent workers, and against public insurance for dependent workers. Hussey and Anderson (2003) compare single-payer and multi-payer models in the areas of revenue collection, risk pooling, purchasing, and social solidarity. Single-payer and multi-payer systems each have advantages which may meet countries' priorities for their health insurance system.

Simon (2005) test predictions about the effect of reforms on the employer-provided health insurance market using both individual-level and employer-level data. He estimates these effects for small firms and their workers using large firms and their workers in the same states, as well as large and small firms and their workers in non-reform states, as comparison groups. Wang et al. (2006) examine adverse selection in a subsidized voluntary health insurance scheme, the Rural Mutual Health Care (RMHC) scheme, in a poor rural 
area of China. Logistic regression is employed for the data analysis. Castano and Zambrano (2006) test the hypothesis that market failures would lead to biased selection favoring new entrants. Two household surveys are analyzed using Self-Reported Health Status and the presence of chronic conditions as prospective indicators of individual risk. Biased selection is found to take place, leading to adverse selection among incumbents, and favorable selection among new entrants.

Gao et al. (2009) study the problem of information asymmetry using data from China's individual health-insurance market. Their preliminary results appear to contradict standard-model predictions, showing that higher-risk buyers are more likely to purchase "additional" insurance than lower-risk buyers, but that they also tend to purchase lower limits of "basic" insurance coverage. They develop a theoretical model to capture the effects of buyers' wealth levels and loss amounts, and show empirically that these effects lead to the coexistence of adverse selection and advantageous selection in China's health-insurance market. Lin (2011) selects and establishes a new, proper Health Technology Assessment system in Taiwan National Health Insurance. Based on analytic hierarch process (AHP) methods, he makes interviews with health officials, health care providers and customers by using the AHP questionnaire. Fuzzy multiple criteria decision making (Fuzzy MCDM) is adopted to proceed the empirical evidence analysis and evaluation on the schemes of HTA systems. Schram and Sonnemans (2011) study decisions and decision strategies in a laboratory experiment where they create a controlled environment that closely mirrors this setting. They use an electronic information board that allows to carefully monitor the individual's decision strategy. The number of alternatives, switching costs, and the speed at which health deteriorates are varied across treatments. They find that most subjects' search is based more on attributes than on policies.

As a result of the literature review it is seen that there is a gap in the multicriteria evaluation of health insurance options under uncertainty conditions. Evaluation criteria for these options are usually expressed in linguistic terms by experts such that "with respect to criterion $\mathrm{X}$, option A is fairly more important than option B". Multicriteria methods under vagueness are needed to capture these linguistic expressions in the evaluation process.

\section{Health insurance options}

Most countries feel constant pressure because expenditure is increasing and resources are scarce. Policy-makers have three options: containing costs, increasing funding for health services or both. Concern about an expenditure crisis in health care has led to the introduction of major changes in how health care is organized and financed. The provision and financing of health care can be simplified as an exchange or transfer of resources: the providers transfer health care resources to patients and patients or third parties transfer financial resources to the providers. Private health insurance premiums are paid by an individual, shared between the employees and the employer or paid wholly by the employer. Government may subsidize the cost of private health insurance using tax credits or tax relief (Mossialos, Dixon 2002).

In today's world, health insurance costs have risen significantly. There are many health insurance options available to the consumers. The resulting financial strain has affected 
corporate and personal budgets alike, and as a result, many people have had to make some hard choices.

Because of the rising costs of traditional insurance plans, consumers are looking for new health insurance options. With Health Savings Accounts (HSAs), a special account owned by an individual in which contributions to the account is to pay for current and future medical expenses. It must be owned and used in conjunction with a high deductible health plan. It can create a platform for asset accumulation over a lifetime. With an HSA, traditionally money may be taken from your paycheck before taxes or you can open up an individual HSA account and contribute money on your own. Your employer or a family member can also contribute to your HSA. The other alternative option that may offer reduced employer costs or more control over health spending is health reimbursement arrangements (HRAs). They let employees and/or employers set aside pre-tax income to cover medical expenses. HRAs allow the employee to use the employer's money solely for medical expenses. The funds are owned by the employer, not by the employee, and they may not be withdrawn for nonmedical expenditures (CAHI.org 2004).

HSAs are similar to flexible spending accounts (FSAs), which also allow the use of pretax income for medical expenses. FSAs are typically used as a supplement to traditional insurance rather than an alternative. With an FSA, money is taken from your paycheck before taxes and put into an account. You can then use that money to pay for medical expenses throughout the year. It's important to understand that FSAs have a "use it or lose it" provision - meaning that you must use the dollars in the year in which they are saved or you will lose them at the end of the year. FSAs allow employees to contribute some of their own salary to an account to pay for health care expenses or their share of health insurance premiums. Like HSAs, contributions to an FSA are exempt from both income and payroll taxes. HSA and HRA funds can be rolled over to the following year so that employees can accumulate savings for unexpected health problems. In contrast, FSAs cannot be rolled over and unused funds must revert to the employer. Contributions to an HSA can be funded by the employer and/or employees. An employer with limited funds could purchase a high-deductible plan and encourage employees to make regular tax-free contributions to an HSA to fund their medical expenses up to the deductible. An HRA can be funded only by employers. HSAs and HRAs are fairly new to the health insurance market. They can help reduce spending by giving employees more direct control over funds spent on their coverage (CAHI.org 2004):

Cardon and Showalter (2007) develop an infinite horizon utility maximization model of the interaction between insurance choice and tax-preferred health savings accounts. The model can be used to examine a wide range of policy options, including flexible spending accounts, health savings accounts, and health reimbursement accounts. They create an analytic framework that is sufficiently flexible to analyze a wide range of policy proposals-HSAs, FSAs, rollover FSAs, HRAs, etc.

\section{Selection criteria for health insurance options}

In the literature many criteria exist for the evaluation of health insurance options. The following selection criteria are obtained from the Council for Affordable Health Insurance (CAHI.org 2004): 


\section{Eligibility (C1)}

All insurance policies have age limits and minimum standards of health for an individual to obtain coverage. Most insurers will not cover someone with a serious or terminal disease, such as AIDS or cancer. Each insurance company, no matter whether they offer health, dental, or life insurance has ways to verify your insurance eligibility and coverage.

In Health Savings Account (HSA), individuals must be below medicare eligibility age and not covered by any other health plan which duplicates any benefits in the qualified high-deductible plan. In Flexible Spending Accounts (FSA) and Health Reimbursement Arrangements (HRAs), individuals must work for an employer who offers one.

\section{Portability (C2)}

Health insurance portability protects workers' access to health insurance when they change or lose their jobs by making sure that pre-existing conditions do not inhibit someone's access to health insurance.

In HSA, rollover is allowed. Individuals own HSA and take it when leaving employment. In FSA, unused funds must be spent by year's end (or by termination of employment before year's end), otherwise individual loses money. HRAs cannot be rolled over to a new employer. An employer is under no obligation to continue the arrangement after employee departure, however an employer may chose to continue reimbursing a former employee's expenses from HRA.

\section{Catch up contribution (C3)}

It is a type of retirement savings contribution that allows people over 50 to make additional contributions to their individual retirement accounts. The catch-up contribution provision was created by the Economic Growth and Tax Relief Reconciliation Act of 2001 (EGTRRA), so that older individuals would be able to set aside enough savings for retirement.

In HSA, individuals age 55 or older may contribute more to the account per year. Starting in 2004, an additional $\$ 500$ contribution is allowed, increasing $\$ 100$ per year, up to $\$ 1,000$ per year in 2009 and thereafter. Married couples may both contribute a catch up contribution to HSA. In FSA and HRA, it is not available.

\section{Ownership (C4)}

HSA and FSA options present individual/employee ownership while HRA does only employer ownership.

\section{Funding (who and how) (C5)}

HSA requires money to be deposited directly into the account. In FSA, a set amount of pretax wages designated by the employee is deposited directly into an account. In HRA, employer reimburses employee when presented with a valid receipt.

\section{Health plan arrangement (C6)}

In HSA, minimum $\$ 1,000$ for individual and $\$ 2,000$ for family coverage are needed. No maximum deductible. Total costs to the insured cannot exceed $\$ 5,000$ for an individual and $\$ 10,000$ for a family, including both the deductible and copays. Thus, a plan that pays $100 \%$ of all costs above the deductible could have a deductible as high as $\$ 5,000$ for an 
individual or $\$ 10,000$ for a family. In FSA and HRA, any type of health plan arrangement is allowed.

\section{Tax treatment (C7)}

Qualified HSAs are tax free as long as funds are spent on medical care. Contributions to FSA are tax free and so reduce annual taxable income. In HRA, reimbursements to employee are tax free as long as they are used on qualified health care purchases.

\section{Usability for non-medical expenses (C8)}

In HSA, funds used for non-medical expenses are taxed as income and incur a $10 \%$ penalty. After age of Medicare eligibility there is no penalty. In FSA and HRA, usability for non-medical expenses is available for only expenses defined by Insurance Research Council.

\section{Multiattribute selection using an integrated fuzzy AHP-TOPSIS methodology}

In the literature to obtain the criteria weights the most used multicriteria method is AHP. It has been used for the solution of various multicriteria problems in the literature (Ginevičius et al. 2004; Wu et al. 2012). The obtained weights from AHP are usually used as inputs to the other multicriteria methods. Even AHP alone or TOPSIS alone has the capability to select the best alternative, we aimed at combining the powerful aspects of these two methods. TOPSIS lets the scores in different units (money, distance, load, etc.) to be directly used in the decision matrix.

\subsection{Fuzzy AHP}

AHP is one of the well-known multi-criteria decision making techniques that was first proposed by Saaty (1980). The classical AHP takes into consideration the definite judgments of decision makers (Wang, Chen 2007).

Although the classical AHP includes the opinions of experts and makes a multiple criteria evaluation, it is not capable of reflecting human's vague thoughts (Seçme et al. 2009; Zolfani et al. 2012). As the uncertainty of information and the vagueness of human feeling and recognition, it is difficult to provide exact numerical values for the criteria and make evaluations which exactly convey the feeling and recognition of objects for decision makers. Therefore, most of the selection parameters cannot be given precisely. Thus experts may prefer intermediate judgments rather than certain judgments. So the fuzzy set theory makes the comparison process more flexible and capable to explain experts' preferences (Kahraman et al. 2003).

Different methods for the fuzzification of AHP have been proposed in the literature. AHP is firstly fuzzified by Laarhoven and Pedrycz (1983), and in this study, fuzzy ratios which were defined by triangular membership functions were compared. Buckley (1985) used the comparison ratios based on trapezoidal membership functions. Chang (1996) introduced a new approach for handling fuzzy AHP, with the use of triangular fuzzy numbers for pair-wise comparison scale of fuzzy AHP, and the use of the extent analysis method for the synthetic extent values of the pair-wise comparisons. Kulak and Kahraman (2005) made a selection among the transportation companies by using fuzzy axiomatic design and fuzzy AHP. They developed fuzzy multi-attribute axiomatic design approach and compared it with fuzzy AHP. 
Buckley (1985) uses the geometric mean method to derive fuzzy weights and performance scores. This method is used because it is easy to extend to the fuzzy case and guarantees a unique solution to the reciprocal comparison matrix. The weight assessing method by geometric mean is chosen for its simplicity and ease in its application to the fuzzy case. The positive reciprocal comparison matrix of criteria weights is given as:

$$
C=\left[\begin{array}{cccc}
C_{11} & C_{12} & \cdots & C_{1 n} \\
C_{21} & C_{22} & \cdots & C_{2 n} \\
\vdots & & & \vdots \\
C_{n 1} & C_{n 2} & \cdots & C_{n n}
\end{array}\right] .
$$

The geometric mean of each row is calculated as:

$$
z_{j}=\left[\prod_{k=1}^{n} C_{j k}\right]^{1 / n} \text { for } j, k=1,2, \ldots, n .
$$

The weight $w_{j}$ is calculated as:

$$
w_{j}=\frac{z_{j}}{z_{1}+z_{2}+\ldots+z_{n}}, \quad \forall j .
$$

To facilitate the calculation of fuzzy weights, the following arithmetic operations of trapezoidal fuzzy numbers are presented. A trapezoidal fuzzy number ( $\operatorname{TrFN}$ ) can be defined as $\tilde{m}=(a, b, c, d)$ where $0 \leq a \leq b \leq c \leq d$ as shown in Figure 1 . The main arithmetic operations of TrFNs can be found in (Chen et al. 2006). A triangular fuzzy number $(a, b, c)$ can be converted to a trapezoidal fuzzy number as $(a, b, b, c)$.

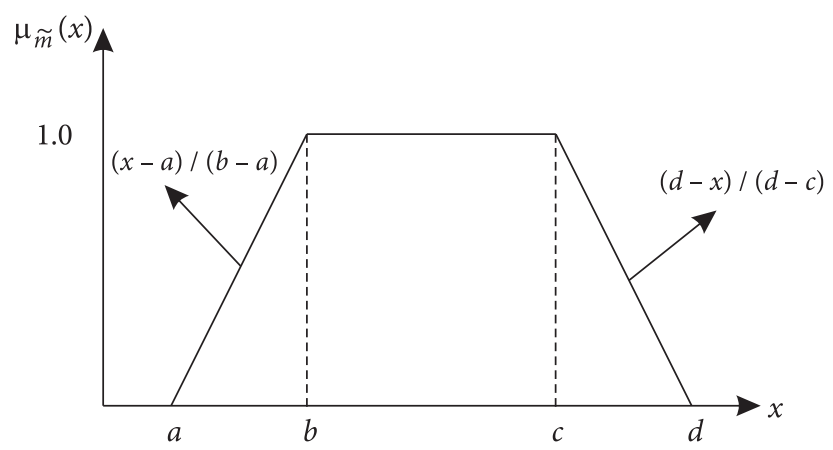

Fig. 1. Membership Function of TrFN

The steps of the fuzzy AHP algorithm can be summarized as follows:

Step 1. Evaluate the relative importance of the criteria using pairwise comparisons. The experts are required to provide their judgments on the basis of their knowledge and expertise. The experts' linguistic preferences are converted into trapezoidal fuzzy numbers using Table 1. 
Table 1. Fuzzy evaluation scale for the weights

\begin{tabular}{ll}
\hline Linguistic terms & Fuzzy score \\
\hline Absolutely Strong (AS) & $(5 / 2,3,7 / 2,4)$ \\
\hline Very Strong (VS) & $(2,5 / 2,3,7 / 2)$ \\
\hline Fairly Strong (FS) & $(3 / 2,2,5 / 2,3)$ \\
\hline Slightly Strong (SS) & $(1,3 / 2,2,5 / 2)$ \\
\hline Equal (E) & $(1,1,1,1)$ \\
\hline Slightly Weak (SW) & $(2 / 5,1 / 2,2 / 3,1)$ \\
\hline Fairly Weak (FW) & $(1 / 3,2 / 5,1 / 2,2 / 3)$ \\
\hline Very Weak (VW) & $(2 / 7,1 / 3,2 / 5,1 / 2)$ \\
\hline Absolutely Weak (AW) & $(1 / 4,2 / 7,1 / 3,2 / 5)$ \\
\hline
\end{tabular}

Step 2. Aggregate experts' individual preferences into group preference by applying the fuzzy trapezoidal averaging operator, which is defined by:

$$
\tilde{C}_{j k}=\frac{1}{K}\left[\tilde{C}_{j k}^{1}(+) \tilde{C}_{j k}^{2}(+) \ldots(+) \tilde{C}_{j k}^{K}\right],
$$

where $K$ is the number of experts and $\tilde{C}_{j}^{K}$ is the evaluation of the $K$ th decision maker on the pairwise importance comparison of $j$ th and kth criteria.

Step 3. Obtain the fuzzy weights $\tilde{w}_{j}$. The derivation of $\tilde{z}_{j}$ values (Eq. (2)) and fuzzy weights $\tilde{w}_{j}$ (Eq. (3)) can be detailed as follows. Let,

$$
a_{j}=\left[\prod_{k=1}^{n} a_{j k}\right]^{1 / n} \text { and } a=\sum_{j=1}^{n} a_{j} .
$$

We can define $b_{j}$ and $b, c_{j}$ and $c$, and $d_{j}$ and $d$. The fuzzy weight $\tilde{w}_{j}$ is determined as (Chen, Hwang 1992):

$$
\tilde{w}_{j}=\left(\frac{a_{j}}{d}, \frac{b_{j}}{c}, \frac{c_{j}}{b}, \frac{d_{j}}{a}\right), \quad \forall j .
$$

Step 4. Defuzzify and normalize the trapezoidal fuzzy weights. To defuzzify the TrFN in Eq. (6), Eq. (7) is used:

$$
w_{j}^{\prime}=\frac{\frac{a_{j}}{d}+2\left(\frac{b_{j}}{c}+\frac{c_{j}}{b}\right)+\frac{d_{j}}{a}}{6} .
$$

Now, to normalize the crisp weights Eq. (8) is used:

$$
w_{j}=\frac{w_{j}^{\prime}}{\sum_{j=1}^{n} w_{j}^{\prime}}, \quad j=1,2, \ldots, n .
$$




\subsection{Fuzzy TOPSIS}

TOPSIS one of the classical multi-criteria decision making methods was developed by Hwang and Yoon (1981). It is based on the concept that the chosen alternative should have the shortest distance from the positive ideal solution (PIS) and the farthest from the negative ideal solution (NIS). TOPSIS also provides an easily understandable and programmable calculation procedure. It has the ability of taking various criteria with different units into account simultaneously (Ekmekçioğlu et al. 2010).

A number of fuzzy TOPSIS methods have been developed in recent years. Chen and Hwang (1992) first applied fuzzy numbers to establish fuzzy TOPSIS. Triantaphyllou and Lin (1996) developed a fuzzy TOPSIS method in which relative closeness for each alternative is evaluated based on fuzzy arithmetic operations. Chen (2000) extended the TOPSIS method to fuzzy group decision making situations by considering triangular fuzzy numbers and defining crisp Euclidean distance between two fuzzy numbers. Chu (2002) and Chu and Lin (2002) further improved the methodology proposed by Chen (2000). Jahanshahloo et al. (2006) and Chu and Lin (2009) extended the fuzzy TOPSIS method based on alpha level sets with interval arithmetic.

Fuzzy TOPSIS has been introduced for various multi-attribute decision-making problems. Yong (2006) used fuzzy TOPSIS for plant location selection and Chen et al. (2006) used fuzzy TOPSIS for supplier selection. Kahraman et al. (2007) utilized fuzzy TOPSIS for industrial robotic system selection. Ekmekçioğlu et al. (2010) used a modified fuzzy TOPSIS to select municipal solid waste disposal method and site. Kaya and Kahraman (2011) proposed a modified fuzzy TOPSIS for selection of the best energy technology alternative. Kim et al. (2011) used fuzzy TOPSIS for modeling consumer's product adoption process. Yu et al. (2011) proposed an evaluation model based on crisp AHP and fuzzy TOPSIS to tackle ranking e-commerce websites in e-alliance in fuzzy environment. The AHP is applied to analyze the structure of ranking problem and to determine weights of the criteria. Fuzzy TOPSIS method is used to obtain final ranking. Aydogan (2011) proposed a conceptual performance measurement framework that takes into account company-level factors for a real world application problem. An integrated approach of analytic hierarchy process (AHP) improved by rough sets theory (RoughAHP) and fuzzy TOPSIS method is proposed to obtain final ranking. Rostamzadeh and Sofian (2011) presented a fuzzy decision-making approach for prioritizing effective 7Ms (Management, Manpower, Marketing, Method, Machine, Material, and Money) to improve production systems performance. Linguistic values are used to assess the ratings and weights for 7Ms. A multiple criteria decision-making model based on fuzzy AHP and fuzzy TOPSIS are applied.

In the following, Chen's fuzzy TOPSIS method is explained:

Chen (2000) extended the TOPSIS method to fuzzy group decision making situations by considering triangular fuzzy numbers and defining crisp Euclidean distance between two fuzzy numbers. In Chen's fuzzy TOPSIS, linguistic preferences can easily be converted to fuzzy numbers which are allowed to be used in calculations (Önüt, Soner 2008; Ekmekçioğlu et al. 2010; Kutlu, Ekmekçioğlu 2010). 
It is suggested that the decision makers use linguistic variables to evaluate the ratings of alternatives with respect to criteria. Table 2 gives the linguistic scale for evaluation of the alternatives. Assuming that a decision group has $K$ people, the ratings of alternatives with respect to each criterion can be calculated as:

$$
\tilde{x}_{i j}=\frac{1}{K}\left[\tilde{x}_{i j}^{1}(+) \tilde{x}_{i j}^{2}(+) \ldots(+) \tilde{x}_{i j}^{K}\right],
$$

where $\tilde{x}_{i j}^{K}$ is the rating of the Kth decision maker for ith alternative with respect to $j$ th criterion (Chen 2000).

Table 2. Fuzzy evaluation scores for the alternatives

\begin{tabular}{lll}
\hline \multicolumn{1}{c}{ Linguistic terms } & \multicolumn{1}{c}{ Triangular fuzzy scores } & \multicolumn{1}{c}{ Trapezoidal fuzzy scores } \\
\hline Very Poor (VP) & $(0,0,10)$ & $(0,0,0,10)$ \\
\hline Poor $(\mathrm{P})$ & $(0,10,30)$ & $(0,10,10,30)$ \\
\hline Medium Poor (MP) & $(10,30,50)$ & $(10,30,30,50)$ \\
\hline Fair (F) & $(30,50,70)$ & $(30,50,50,70)$ \\
\hline Medium Good (MG) & $(50,70,90)$ & $(50,70,70,90)$ \\
\hline Good (G) & $(70,90,100)$ & $(70,90,90,100)$ \\
\hline Very Good (VG) & $(90,100,100)$ & $(90,100,100,100)$ \\
\hline
\end{tabular}

Obtaining weights of the criteria and fuzzy ratings of alternatives with respect to each criterion, the fuzzy multi-criteria decision-making problem can be expressed in matrix format as:

$$
\begin{gathered}
D=\left[\begin{array}{cccc}
\tilde{x}_{11} & \tilde{x}_{12} & \ldots & \tilde{x}_{1 n} \\
\vdots & \vdots & \ldots & \vdots \\
\tilde{x}_{m 1} & \tilde{x}_{m 2} \ldots & \tilde{x}_{m n}
\end{array}\right], \\
W=\left[w_{1}, w_{2}, \ldots, w_{n}\right], \quad j=1,2, \ldots, n,
\end{gathered}
$$

where $\tilde{x}_{i j}$ is the rating of the alternative $A_{i}$ with respect to criterion $j$ (i.e. $C_{j}$ ) and $w_{j}$ denotes the importance weight of $C_{j}$. These linguistic variables can be described by triangular fuzzy numbers: $\tilde{x}_{i j}=\left(a_{i j}, b_{i j}, c_{i j}\right)$. To avoid the complicated normalization formula used in classical TOPSIS, the linear scale transformation is used here to transform the various criteria scales into a comparable scale. Therefore, we can obtain the normalized fuzzy decision matrix denoted by $\tilde{R}$ :

$$
\tilde{R}=\left[\tilde{r}_{i j}\right]_{m x n},
$$

where $B$ and $C$ are the set of benefit criteria and cost criteria, respectively, and

$$
\begin{aligned}
& \tilde{r}=\left(\frac{\tilde{a}_{i j}}{c_{j}^{*}}, \frac{\tilde{b}_{i j}}{c_{j}^{*}}, \frac{\tilde{c}_{i j}}{c_{j}^{*}}\right), \quad j \in B ; \\
& \tilde{r}=\left(\frac{a_{j}^{-}}{c_{i j}}, \frac{a_{j}^{-}}{b_{i j}}, \frac{a_{j}^{-}}{a_{i j}}\right), \quad j \in C ;
\end{aligned}
$$




$$
\begin{aligned}
& c_{j}^{*}=\max _{i} c_{i j} \text { if } j \in B ; \\
& a_{j}^{-}=\min _{i} a_{i j} \text { if } j \in C .
\end{aligned}
$$

The normalization method mentioned above is to preserve the property that the ranges of normalized triangular fuzzy numbers belong to [0;1].

Considering the different importance of each criterion, we can construct the weighted normalized fuzzy decision matrix as:

where

$$
\tilde{V}=\left[\tilde{v}_{i j}\right]_{m x n}, i=1,2, \ldots, m ; j=1,2, \ldots, n,
$$

$$
\tilde{v}_{i j}=\tilde{r}_{i j}(.) d\left(C_{j}\right) .
$$

According to the weighted normalized fuzzy decision matrix, we know that the elements $\tilde{v}_{i j} \forall i, j$ are normalized positive triangular fuzzy numbers and their ranges belong to the closed interval $[0,1]$. Then, we can define the fuzzy positive-ideal solution $\left(F P I S, A^{*}\right)$ and fuzzy negative-ideal solution $\left(F N I S, A^{-}\right)$as:

$$
\begin{aligned}
& A^{*}=\left(\tilde{v}_{1}^{*}, \tilde{v}_{2}^{*}, \ldots, \tilde{v}_{n}^{*}\right) ; \\
& A^{-}=\left(\tilde{v}_{1}^{-}, \tilde{v}_{2}^{-}, \ldots, \tilde{v}_{n}^{-}\right),
\end{aligned}
$$

where

$$
\tilde{v}_{j}^{*}=(1,1,1) \text { and } \tilde{v}_{j}^{-}=(0,0,0), j=1,2, \ldots, n .
$$

The distance of each alternative from $A^{*}$ and $A^{-}$can be currently calculated as:

$$
\begin{aligned}
& d_{i}^{*}=\sum_{j=1}^{n} d\left(\tilde{v}_{i j}, \tilde{v}_{j}^{*}\right), i=1,2, \ldots, m ; \\
& d_{i}^{-}=\sum_{j=1}^{n} d\left(\tilde{v}_{i j}, \tilde{v}_{j}^{-}\right), i=1,2, \ldots, m,
\end{aligned}
$$

where $d(.,$.$) is the distance measurement between two fuzzy numbers calculating with the$ following formula:

$$
d(\tilde{\rho}, \tilde{\tau})=\sqrt{\frac{1}{3}\left[\left(\rho_{1}-\tau_{1}\right)^{2}+\left(\rho_{2}-\tau_{2}\right)^{2}+\left(\rho_{3}-\tau_{3}\right)^{2}\right]},
$$

where $\tilde{\rho}=\left(\rho_{1}, \rho_{2}, \rho_{3}\right)$ and $\tilde{\tau}=\left(\tau_{1}, \tau_{2}, \tau_{3}\right)$ are two triangular fuzzy numbers.

A closeness coefficient is defined to determine the ranking order of all alternatives once the $\tilde{d}_{j}^{*}$ and $\tilde{d}_{j}^{-}$of each alternative $A_{i}(i=1,2, \ldots, m)$ are calculated. The closeness coefficient of each alternative is calculated as:

$$
C C_{i}=\frac{\tilde{d}_{j}^{-}}{\tilde{d}_{j}^{*}+\tilde{d}_{j}^{-}}, i=1,2, \ldots, m .
$$

Obviously, an alternative $A_{i}$ is closer to the (FPIS, $\mathrm{A}^{*}$ ) and farther from (FPIS, $\mathrm{A}^{-}$) as $\mathrm{CC}_{\mathrm{i}}$ approaches to 1 . Therefore, according to the closeness coefficient, we can determine the ranking order of all alternatives and select the best one from among a set of feasible alternatives. 


\section{Application of the methodology}

\subsection{Selection among health insurance options}

The considered three insurance options are evaluated with respect to the following eight criteria: Eligibility (C1), Portability (C2), Catch up contribution (C3), Ownership (C4), Funding (C5), Health plan arrangement (C6), Tax treatment (C7), and Usability for non-medical expenses (C8).

Five experts from three insurance companies in Turkey determined the criteria weights by the pairwise comparison matrix in Table 3 using the fuzzy evaluation scale in Table 1 . The fuzzy scores in the matrix are the compromised values.

Using Eq. (7) in Buckley's (1985) fuzzy AHP method, the criteria weights given in Table 4 are obtained. The consistency of the defuzzified pairwise comparison matrix was measured and found to be 0.02 .

Table 3. Pairwise comparison matrix of criteria using linguistic terms

\begin{tabular}{ccccccccc}
\hline & C1 & C2 & C3 & C4 & C5 & C6 & C7 & C8 \\
\hline C1 & E & FS & AS & AS & SS & FS & AS & AS \\
\hline C2 & FW & E & SS & SS & FW & SW & SS & SS \\
\hline C3 & AW & SW & E & E & VW & FW & E & E \\
\hline C4 & AW & SW & E & E & VW & FW & E & E \\
\hline C5 & SW & FS & VS & VS & E & SS & AS & AS \\
\hline C6 & FW & SS & FS & FS & SW & E & FS & FS \\
\hline C7 & AW & SW & E & E & AW & FW & E & E \\
\hline C8 & AW & SW & E & E & AW & FW & E & E \\
\hline
\end{tabular}

Table 4. Criteria weights

\begin{tabular}{cccccccc}
\hline C1 & C2 & C3 & C4 & C5 & C6 & C7 & C8 \\
\hline 0.25 & 0.11 & 0.07 & 0.07 & 0.21 & 0.15 & 0.07 & 0.07 \\
\hline
\end{tabular}

According to the results in Table 5, the priority vector of the criteria gives us the ranking order as C1 (eligibility) > C5 (funding) > C6 (health plan arrangement) > C2 (portability) > $\mathrm{C} 3($ catch up contribution $)=\mathrm{C} 4($ ownership $)=\mathrm{C} 7($ tax treatment $)=\mathrm{C} 8$ (usability for non medical expenses).

After obtaining the criteria weights, the fuzzy decision matrix, which are composed of compromise values are generated by the five experts as in Table 5. The fuzzy normalized decision matrix is given in Table 6. To obtain the fuzzy normalized decision matrix Eqs (13-14) were used for benefits and cost criteria, respectively. The fuzzy weighted normalized decision matrix is presented in Table 7 . The values in Table 7 were obtained by multiplying the values in Table 6 with the criteria weights in Table 4. The distances to the fuzzy positive ideal solution and the fuzzy negative ideal solution values are given in Table 8 . The values in Table 8 were obtained by using Eq. (24). The closeness coefficients and ranking order of the three alternatives are presented in Table 9. The values in Table 9 were obtained by using Eqs (22), (23), and (25). 
Table 5. Fuzzy decision matrix

\begin{tabular}{ccccccccc}
\hline \multirow{2}{*}{ OP- } & \multicolumn{7}{c}{ CRITERIA } \\
\cline { 2 - 9 } TIONS & $\mathrm{C} 1$ & $\mathrm{C} 2$ & $\mathrm{C} 3$ & $\mathrm{C} 4$ & $\mathrm{C} 5$ & $\mathrm{C} 6$ & $\mathrm{C} 7$ & $\mathrm{C} 8$ \\
\hline \multirow{2}{*}{ HSA } & $\begin{array}{c}75,80, \\
85)\end{array}$ & $\begin{array}{c}(90,95, \\
100)\end{array}$ & $\begin{array}{c}(80,90, \\
100)\end{array}$ & $\begin{array}{c}(90,95, \\
100)\end{array}$ & $\begin{array}{c}(35,40, \\
45)\end{array}$ & $\begin{array}{c}(35,45, \\
55)\end{array}$ & $\begin{array}{c}(45,55, \\
65)\end{array}$ & $\begin{array}{c}(65,70, \\
75)\end{array}$ \\
\hline \multirow{2}{*}{ FSA } & $\begin{array}{c}60,65, \\
70)\end{array}$ & $\begin{array}{c}(75,80, \\
85)\end{array}$ & $\begin{array}{c}(35,40, \\
45)\end{array}$ & $\begin{array}{c}(90,95, \\
100)\end{array}$ & $\begin{array}{c}(65,70, \\
75)\end{array}$ & $\begin{array}{c}(80,85, \\
90)\end{array}$ & $\begin{array}{c}(75,80, \\
85)\end{array}$ & $\begin{array}{c}(35,40, \\
45)\end{array}$ \\
\hline HRA & $\begin{array}{c}55,65, \\
75)\end{array}$ & $\begin{array}{c}(50,60, \\
70)\end{array}$ & $\begin{array}{c}(35,40, \\
45)\end{array}$ & $\begin{array}{c}(45,50, \\
55)\end{array}$ & $\begin{array}{c}(90,95, \\
100)\end{array}$ & $\begin{array}{c}(80,85, \\
90)\end{array}$ & $\begin{array}{c}(45,55, \\
65)\end{array}$ & $\begin{array}{c}(35,40, \\
45)\end{array}$ \\
\hline $\begin{array}{l}\text { Criteria } \\
\text { Weights }\end{array}$ & 0.25 & 0.11 & 0.07 & 0.07 & 0.21 & 0.15 & 0.07 & 0.07 \\
\hline
\end{tabular}

Table 6. Fuzzy normalized decision matrix

\begin{tabular}{|c|c|c|c|c|}
\hline \multirow{2}{*}{ OPTIONS } & \multicolumn{4}{|c|}{ CRITERIA } \\
\hline & $\mathrm{C} 1$ & C2 & C3 & C4 \\
\hline HSA & $(0.8824,0.9412,1)$ & $(0.9,0.95,1)$ & $(0.8,0.9,1)$ & $(0.9,0.95,1)$ \\
\hline FSA & $\begin{array}{c}(0.7059,0.7647 \\
0.8235)\end{array}$ & $(0.75,0.8,0.85)$ & $(0.35,0.4,0.45)$ & $(0.9,0.95,1)$ \\
\hline HRA & $\begin{array}{c}(0.6471,0.7647 \\
0.8824)\end{array}$ & $(0.5,0.6,0.7)$ & $(0.35,0.4,0.45)$ & $(0.45,0.5,0.55)$ \\
\hline OPTIONS & C5 & C6 & $\mathrm{C} 7$ & $\mathrm{C} 8$ \\
\hline HSA & $(0.35,0.4,0.45)$ & $\begin{array}{c}(0.3889,0.5 \\
0.6111)\end{array}$ & $\begin{array}{c}(0.5294,0.6471 \\
0.7647)\end{array}$ & $\begin{array}{c}(0.8667,0.9333, \\
1)\end{array}$ \\
\hline FSA & $(0.65,0.7,0.75)$ & $\begin{array}{c}(0.8889,0.9444 \\
1)\end{array}$ & $\begin{array}{c}(0.8824,0.9412 \\
1)\end{array}$ & $\begin{array}{c}(0.4667,0.5333 \\
0.6)\end{array}$ \\
\hline HRA & $(0.9,0.95,1)$ & $(0.8889,0.9444,1)$ & $\begin{array}{c}(0.5294,0.6471 \\
0.7647)\end{array}$ & $\begin{array}{c}(0.4667,0.5333, \\
0.6)\end{array}$ \\
\hline
\end{tabular}

Table 7. Fuzzy weighted normalized decision matrix

\begin{tabular}{lcccc}
\hline \multirow{2}{*}{ OPTIONS } & \multicolumn{4}{c}{ CRITERIA } \\
\cline { 2 - 5 } & $\mathrm{C} 1$ & $\mathrm{C} 2$ & $\mathrm{C} 3$ & $\mathrm{C} 4$ \\
\hline \multirow{2}{*}{ HSA } & $(0.2206,0.2353$, & $(0.0990,0.1045$, & $(0.0560,0.0630$, & $(0.0630,0.0665$, \\
& $0.25)$ & $0.11)$ & $0.07)$ & $0.07)$ \\
\hline \multirow{2}{*}{ FSA } & $(0.1765,0.1912$, & $(0.0825,0.0880$, & $(0.0245,0.0280$, & $(0.0630,0.0665$, \\
& $0.2059)$ & $0.0935)$ & $0.0315)$ & $0.07)$ \\
\hline \multirow{2}{*}{ HRA } & $(0.1618,0.1912$, & $(0.0550,0.0660$, & $(0.0245,0.0280$, & $(0.0315,0.0350$, \\
& $0.2206)$ & $0.0770)$ & $0.0315)$ & $0.0385)$ \\
\hline \multirow{2}{*}{ OPTIONS } & $\mathrm{C} 5$ & $\mathrm{C} 6$ & $\mathrm{C} 7$ & $\mathrm{C} 8$ \\
\hline \multirow{2}{*}{ HSA } & $(0.0735,0.0840$, & $(0.0583 .0 .0750$, & $(0.0371,0.0453$, & $(0.0607,0.0653$, \\
& $0.0945)$ & $0.0917)$ & $0.0535)$ & $0.07)$ \\
\hline \multirow{2}{*}{ FSA } & $(0.1365,0.1470$, & $(0.1333,0.1417$, & $(0.0618,0.0659$, & $(0.0327,0.0373$, \\
& $0.1575)$ & $0.15)$ & $0.07)$ & $0.0420)$ \\
\hline \multirow{2}{*}{ HRA } & $(0.1890,0.1995$, & $(0.1333,0.1417$, & $(0.0371,0.0453$, & $(0.0327,0.0373$, \\
& $0.21)$ & $0.15)$ & $0.0535)$ & $0.0420)$ \\
\hline
\end{tabular}


Table 8. Distance measurements

\begin{tabular}{lcc}
\hline \multicolumn{1}{c}{ OPTIONS } & (FPIS) & (FNIS) \\
\hline HSA & 7.2614 & 0.7419 \\
\hline FSA & 7.2346 & 0.7669 \\
\hline HRA & 7.2565 & 0.7474 \\
\hline
\end{tabular}

Table 9. Closeness coefficients and ranking order of the three alternatives

\begin{tabular}{lcc}
\hline OPTIONS & $\begin{array}{c}\text { CLOSENESS } \\
\text { COEFFICIENTS }\end{array}$ & $\begin{array}{c}\text { ORDER OF THE } \\
\text { ALTERNATIVES }\end{array}$ \\
\hline HSA & 0.8441 & 3 \\
\hline FSA & 0.8730 & 1 \\
\hline HRA & 0.8504 & 2 \\
\hline
\end{tabular}

\subsection{Sensitivity analysis}

In order to see the effects of the changes in the weights of the criteria, a sensitivity analysis has been realized. The six different cases given in Table 10 have been examined and the obtained results have been illustrated in Figure 2. In the sensitivity analysis, new weights were obtained by using slightly modified pairwise comparison matrices of AHP to see if these slight changes affected the ranking of alternatives. Accordingly the obtained weights were used as inputs to TOPSIS.

Table 10. Criteria weights of six different cases

\begin{tabular}{lcccccccc}
\hline & \multicolumn{7}{c}{ CRITERIA WEIGHTS } \\
\cline { 2 - 9 } & C1 & C2 & C3 & C4 & C5 & C6 & C7 & C8 \\
\hline Case 1 & 0.250 & 0.110 & 0.070 & 0.070 & 0.210 & 0.150 & 0.070 & 0.070 \\
\hline Case 2 & 0.035 & 0.211 & 0.199 & 0.051 & 0.218 & 0.034 & 0.179 & 0.073 \\
\hline Case 3 & 0.199 & 0.059 & 0.018 & 0.132 & 0.237 & 0.066 & 0.189 & 0.100 \\
\hline Case 4 & 0.020 & 0.236 & 0.191 & 0.126 & 0.092 & 0.111 & 0.096 & 0.128 \\
\hline Case 5 & 0.140 & 0.010 & 0.050 & 0.050 & 0.450 & 0.250 & 0.049 & 0.001 \\
\hline Case 6 & 0.005 & 0.200 & 0.150 & 0.005 & 0.280 & 0.180 & 0.010 & 0.170 \\
\hline
\end{tabular}

Case 1 represents the ranking order of the results obtained by the criteria weights originally assigned by the experts. According to Case 1, FSA is the best option. In the following, sensitivity results are interpreted with respect to the original criteria weights used in Case 1.

In Case 2, the weights of the criteria C2 (portability), C3 (catch up contribution), and C7 (tax treatment) are significantly increased while the weight of C6 (health plan arrangement) is significantly decreased. This caused HSA to be the best option. In Case 3, the weights of the criteria C4 (ownership) and C7 (tax treatment) are significantly increased while the weight of C1 (eligibility), C2 (portability), and C6 (health plan arrangement) are significantly decreased. 


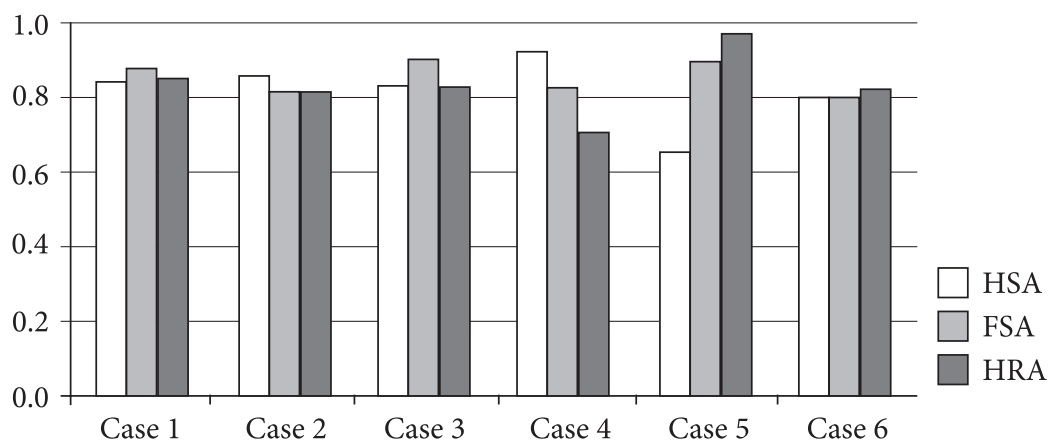

Fig. 2. Results of six different cases

This changed the ranking order of HSA and HRA. In Case 4, the weights of the criteria C2 (portability), C3 (catch up contribution), C4 (ownership), and C8 (usability for non-medical expenses) are significantly increased while the weight of C1 (eligibility) and C5 (funding) are significantly decreased. This caused HSA to be the best option. In Case 5, the weights of the criteria C5 (funding) and C6 (health plan arrangement) are significantly increased while the weights of C1 (eligibility), C2 (portability), and C8 (usability for non-medical expenses) are significantly decreased. This caused HRA to be the best option. In Case 6, the weights of the criteria C2 (portability), C3 (catch up contribution), C5 (funding), and C8 (usability for non-medical expenses) are significantly increased while the weights of $\mathrm{C} 1$ (eligibility), C4 (portability), and C7 (tax treatment) are significantly decreased. This caused HRA to be the best option. This changed the ranking order of HSA and FSA.

The results of Case 4 and Case 5 are remarkable. The weights of the criteria C2, C3, C4, $\mathrm{C} 7$, and C8 are significantly decreased while the weights of $\mathrm{C} 1, \mathrm{C} 5$, and C6 are significantly increased. The ranking order in Case 4 is HSA $>$ FSA $>$ HRA while it is HRA $>$ FSA $>$ HAS in Case 5. This is because of that individuals own HSA and takes it when leaving employment but HRAs cannot be rolled over to a new employer. Similar comments are valid for the others.

Sensitivity analyses show that the decision given by the expected values of criteria weights does not change unless large deviations occur in these expected values.

\section{Conclusions}

Employers may either choose to provide various insurance products from which workers can choose or could increase wages but not offer any health coverage allowing workers to decide how to spend that extra money to meet their health care needs. Employees may have a difficulty in selecting the best health insurance product to meet their needs since it is a complex problem including many dimensions.

We proposed a fuzzy integrated multiattribute decision making methodology based on AHP and TOPSIS. The criteria weights have been obtained by fuzzy AHP and health insurance options weighted by these weights have been evaluated by fuzzy TOPSIS. Our methodology has the advantage of using linguistics expressions instead of sharp numerical data. 
Sensitivity analyses show that the decision given by the expected values of criteria weights does not change unless large deviations occur in these expected values.

The compromised assessments from the experts were received in our case. Some aggregation methods can be used when separate assessments come from experts. As a limitation of our methodology, if the number of criteria gets larger, the process of obtaining criteria weights become impossible with sufficient consistency.

In addition to the theoretical contributions of the proposed method, our study is expected to provide new insights for practical insurance management. In the present case insurance managers should advice FSA option to their customers. The proposed method can be used to consider new insurance options and market conditions by the management.

For further research we suggest that other multicriteria decision making methods like fuzzy VIKOR, fuzzy ELECTRE or fuzzy utility models. The obtained results by these methods can be compared by our results.

\section{References}

Armstrong, J. 2010. Risk equalisation and voluntary health insurance markets: the case of Ireland, Health Policy 98(1): 15-26. http://dx.doi.org/10.1016/j.healthpol.2010.06.010

Atanasova, E.; Pavlova, M.; Velickovski, R.; Nikov, B.; Moutafova, E.; Groot, W. 2011. What have 10 years of health insurance reforms brought about in Bulgaria? Re-appraising the Health Insurance Act of 1998, Health Policy 102(2-3): 263-269. http://dx.doi.org/10.1016/j.healthpol.2010.12.001

Aydogan, E. 2011. Performance measurement model for Turkish aviation firms using the rough-AHP and TOPSIS methods under fuzzy environment, Expert Systems with Applications 38(4): 3992-3998. http://dx.doi.org/10.1016/j.eswa.2010.09.060

Bartholomée, Y.; Maarse, H. 2007. Empowering the chronically ill? Patient collectives in the new Dutch health insurance system, Health Policy 84(2-3): 162-169.

http://dx.doi.org/10.1016/j.healthpol.2007.03.008

Basaza, R.; Criel, B.; Van der Stuyft, P. 2008. Community health insurance in Uganda: why does enrolment remain low? A view from beneath, Health Policy 87(2): 172-184.

http://dx.doi.org/10.1016/j.healthpol.2007.12.008

Buckley, J. J. 1985. Fuzzy hierarchical analysis, Fuzzy Sets Systems 17(1): 233-247. http://dx.doi.org/10.1016/0165-0114(85)90090-9

CAHI.org. 2004. The Council for Affordable Health Insurance's issues and answers: solutions for today's health policy challenges [online]. The Council for Affordable Health Insurance [cited 10 January 2012]. Available from Internet: http://www.cahi.org/cahi_contents/resources/pdf/n124HSAFSAHRAFebruary10pdf.pdf

Carapinha, L. J.; Ross-Degnan, D.; Desta, T. A.; Wagner, K. A. 2011. Health insurance systems in five Sub-Saharan African countries: medicine benefits and data for decision making, Health Policy 99(3): 93-202. http://dx.doi.org/10.1016/j.healthpol.2010.11.009

Cardon, J. H.; Showalter, M. 2007. Insurance choice and tax-preferred health savings accounts, Journal of Health Economics 26(2): 373-399. http://dx.doi.org/10.1016/j.jhealeco.2006.10.010

Castano, R.; Zambrano, A. 2006. Biased selection within the social health insurance market in Colombia, Health Policy 79: 313-324. http://dx.doi.org/10.1016/j.healthpol.2006.01.010

Chang, D.Y. 1996. Applications of the extent analysis method on fuzzy AHP, European Journal of Operational Research 95: 649-655. http://dx.doi.org/10.1016/0377-2217(95)00300-2 
Chen, C. 2000. Extensions of the TOPSIS for group decision-making under fuzzy environment, Fuzzy Sets and Systems 114: 1-9. http://dx.doi.org/10.1016/S0165-0114(97)00377-1

Chen, C.-T.; Lin, C.-T.; Huang, S.-F. 2006. A fuzzy approach for supplier evaluation and selection in supply chain management, International Journal of Production Economics 102(2): 289-301. http://dx.doi.org/10.1016/j.ijpe.2005.03.009

Chen, S. J.; Hwang, C. L. 1992. Fuzzy multi attribute decision making. Lecture Notes in Economics and Mathematical System Series, vol. 375. New York: Springer-Verlag. http://dx.doi.org/10.1007/978-3-642-46768-4

Chu, T. 2002. Selecting plant location via a fuzzy TOPSIS approach, International Journal of Advanced Manufacturing Technology 20: 859-864. http://dx.doi.org/10.1007/s001700200227

Chu, T.; Lin, Y. 2002. Improved extensions of the TOPSIS for group decision making under fuzzy environment, Journal of Information and Optimization Sciences 23: 273-286. http://dx.doi.org/10.1080/02522667.2002.10698996

Chu, T.-C.; Lin, Y.-C. 2009. An interval arithmetic based fuzzy TOPSIS model, Expert Systems with Applications 36: 10870-10876. http://dx.doi.org/10.1016/j.eswa.2009.01.083

Connelly, B. L.; Paolucci, F.; Butler, R. G. J.; Collins, P. 2010. Risk equalisation and voluntary health insurance markets: the case of Australia, Health Policy 98(1): 3-14. http://dx.doi.org/10.1016/j.healthpol.2010.06.002

Devlin, A. R.; Sarma, S.; Zhang, Q. 2011. The role of supplemental coverage in a universal health insurance system: some Canadian evidence, Health Policy 100(1): 81-90. http://dx.doi.org/10.1016/j.healthpol.2010.08.011

Dror, M. D.; Radermacher, R.; Koren, R. 2007. Willingness to pay for health insurance among rural and poor persons: field evidence from seven micro health insurance units in India, Health Policy 82(1): 12-27. http://dx.doi.org/10.1016/j.healthpol.2006.07.011

Ekmekçioğlu, M.; Kaya, T.; Kahraman, C. 2010. Fuzzy multicriteria disposal method and site selection for municipal solid waste, Waste Management 30: 1729-1736. http://dx.doi.org/10.1016/j.wasman.2010.02.031

Gameren, E. 2010. Health insurance and use of alternative medicine in Mexico, Health Policy 98(1): 50-57. http://dx.doi.org/10.1016/j.healthpol.2010.04.006

Gao, F.; Powers, R. M.; Wang, J. 2009. Adverse selection or advantageous selection? Risk and underwriting in China's health-insurance market, Insurance: Mathematics and Economics 44(3): 505-510. http://dx.doi.org/10.1016/j.insmatheco.2009.02.004

Ginevičius, R.; Podvezko, V.; Andruškevičius, A. 2004. Determining of technological effectiveness of building systems by AHP method, Technological and Economic Development of Economy 10(4): 135-141.

Hwang, C. L.; Yoon, K. 1981. Multiple attributes decision making methods and applications. Berlin: Springer. http://dx.doi.org/10.1007/978-3-642-48318-9

Hussey, P.; Anderson, G. F. 2003. A comparison of single and multi-payer health insurance systems and options for reform, Health Policy 66: 215-228. http://dx.doi.org/10.1016/S0168-8510(03)00050-2

Iarossi, M. K.; Helms, M. M. 2002. An employer's choice fully-insured vs. self-insured for group health insurance, Employee Assistance Quarterly 17(4): 1-13. http://dx.doi.org/10.1300/J022v17n04_01

Jack, W. 2001. Controlling selection incentives when health insurance contracts are endogenous, Journal of Public Economics 80(1): 25-48. http://dx.doi.org/10.1016/S0047-2727(00)00103-1

Jahanshahloo, G. R.; Hosseinzadeh, L.; Izadikhah, M. 2006. Extension of the TOPSIS method for decisionmaking problems with fuzzy data, Applied Mathematics and Computation 181: 1544-1551.

Kahraman, C.; Cebeci, U.; Ulukan, Z. 2003. Multi-criteria supplier selection using fuzzy AHP, Logistics Information Management: an International Journal 16(6): 382-394.

http://dx.doi.org/10.1108/09576050310503367 
Kahraman, C.; Çevik, S.; Ateş, N. Y.; Gülbay, M. 2007. Fuzzy multi-criteria evaluation of industrial robotic systems, Computers \& Industrial Engineering 52: 414-433. http://dx.doi.org/10.1016/j.cie.2007.01.005

Kaya, T.; Kahraman, C. 2011. Multicriteria decision making in energy planning using a modified fuzzy TOPSIS methodology, Expert Systems with Applications 38: 6577-6585.

http://dx.doi.org/10.1016/j.eswa.2010.11.081

Kim, S.; Lee, K.; Cho, J. K.; Kim, C. O. 2011. Agent-based diffusion model for an automobile market with fuzzy TOPSIS-based product adoption process, Expert Systems with Applications 38: 7270-7276. http://dx.doi.org/10.1016/j.eswa.2010.12.024

Kulak, O.; Kahraman, C. 2005. Fuzzy multi attribute selection among transportation companies using axiomatic design and analytic hierarchy process, Information Sciences 170: 191-210. http://dx.doi.org/10.1016/j.ins.2004.02.021

Kutlu, A. C.; Ekmekçioğlu, M. 2010. Fuzzy failure modes \& effects analysis by using fuzzy TOPSIS integrated with fuzzy AHP, Proceedings of 1st International Symposium on Computing in Science \& Engineering, 03-05 June 2010, Kuşadas1, Aydın, Turkey, 706-713.

Laarhoven, P. M. J.; Pedrycz, W. 1983. A fuzzy extension of Saaty's priority theory, Fuzzy Sets and Systems 11: 229-241.

Lee, Y. S.; Chun, B. C.; Lee, G. Y.; Seo, K. N. 2008. The national health insurance system as one type of new typology: the case of South Korea and Taiwan, Health Policy 85(1): 105-113. http://dx.doi.org/10.1016/j.healthpol.2007.07.006

Lin, C. W. 2011. Applying fuzzy multiple criteria decision making to establish a new health technology assessment system with coverage implications in Taiwan National Health Insurance, Value in Health 14(3): A26-A27.

Mechanic, D. 1989. Consumer choice among health insurance options, Health Affairs 8(1): 138-148. http://dx.doi.org/10.1377/hlthaff.8.1.138

Mossialos, E.; Dixon, A. 2002. Funding health care: an introduction, in E. Mossialos, A. Dixon, J. Figueras, J. Kutzin (Eds.). Funding health care: options for Europe. Open University Press.

Önüt, S.; Soner, S. 2008. Transshipment site selection using the AHP and TOPSIS under fuzzy environment, Waste Management 28(9): 1552-1559.

Rostamzadeh, R.; Sofian, S. 2011. Prioritizing effective 7Ms to improve production systems performance using fuzzy AHP and fuzzy TOPSIS (case study), Expert Systems with Applications 38: 5166-5177. http://dx.doi.org/10.1016/j.eswa.2010.10.045

Saaty, T. L. 1980. The analytic hierarchy process. New York: McGraw-Hill Book Company.

Sapelli, C.; Vial, B. 2003. Self-selection and moral hazard in Chilean health insurance, Journal of Health Economics 22(3): 459-476. http://dx.doi.org/10.1016/S0167-6296(02)00121-2

Schram, A.; Sonnemans, J. 2011. How individuals choose health insurance: an experimental analysis, European Economic Review 55(6): 799-819. http://dx.doi.org/10.1016/j.euroecorev.2011.01.001

Seçme, N. Y.; Bayrakdaroğlu, A.; Kahraman, C. 2009. Fuzzy performance evaluation in Turkish banking sector using analytic hierarchy process and TOPSIS, Experts Systems with Applications 36: 1169911709. http://dx.doi.org/10.1016/j.eswa.2009.03.013

Simon, I. K. 2005. Adverse selection in health insurance markets? Evidence from state small-group health insurance reforms, Journal of Public Economics 89(9-10): 1865-1877.

http://dx.doi.org/10.1016/j.jpubeco.2004.07.003

Triantaphyllou, E.; Lin, C. L. 1996. Development and evaluation of five fuzzy multi-attribute decision making methods, International Journal of Approximate Reasoning 14: 281-310. http://dx.doi.org/10.1016/0888-613X(95)00119-2

Wagstaff, A.; Lindelow, M. 2008. Can insurance increase financial risk?: The curious case of health insurance in China, Journal of Health Economics 27(4): 990-1005.

http://dx.doi.org/10.1016/j.jhealeco.2008.02.002 
Wang, H.; Zhang, L.; Yip, W.; Hsiao, W. 2006. Adverse selection in a voluntary Rural Mutual Health Care health insurance scheme in China, Social Science \& Medicine 63: 1236-1245.

http://dx.doi.org/10.1016/j.socscimed.2006.03.008

Wang, T. C.; Chen, Y. H. 2007. Applying consistent fuzzy preference relations to partnership selection, International Journal of Management Science 35: 384-388.

Wu, W.; Kou, G.; Peng, Y.; Ergu, D. 2012. Improved AHP-group decision making for investment strategy selection, Technological and Economic Development of Economy 18(2): 299-316. http://dx.doi.org/10.3846/20294913.2012.680520

Yong, D. 2006. Plant location selection based on fuzzy TOPSIS, International Journal of Advanced Manufacturing Technologies 28: 839-844. http://dx.doi.org/10.1007/s00170-004-2436-5

Yu, X.; Guo, S.; Guo, J.; Huang, X. 2011. Rank B2C e-commerce websites in e-alliance based on AHP and fuzzy TOPSIS, Expert Systems with Applications 38(4): 3550-3557. http://dx.doi.org/10.1016/j.eswa.2010.08.143

Zadeh, L. A. 1965. Fuzzy sets, Information and Control 3: 338-353. http://dx.doi.org/10.1016/S0019-9958(65)90241-X

Zolfani, S. H.; Sedaghat, M.; Zavadskas, E. K. 2012. Performance evaluating of rural ICT centers (telecenters), applying fuzzy AHP, SAW-G and TOPSIS Grey, a case study in Iran, Technological and Economic Development of Economy 18(2): 364-387. http://dx.doi.org/10.3846/20294913.2012.685110

Cengiz KAHRAMAN is a full Professor at Industrial Engineering Department of Istanbul Technical University (ITU). His research areas are engineering economics, quality management, statistical decision making, multicriteria decision making, and fuzzy decision making. He published about 170 journal papers and about 150 conference papers. He is in the editorial boards of many international journals and edited about 10 international books from Springer and Atlantis Press. He guest-edited many special issues of international journals and organized international conferences. He was the vice dean of Management Faculty between the years 2004-2007 and the head of Industrial Engineering Department between the years 2010-2013.

Asli SUDER is a full Professor of Management and Organization at Istanbul Technical University, Faculty of Management and Department of Management Engineering, in Turkey. She was graduated from Bosporus University Department of Management in 1976. She continued her education and also earned a Bachelor's Degree in Economics and Administrative Sciences from Marmara University, in 1981, a Master's Degree in International Management from Istanbul University, in 1982, and finally a Philosophy Degree in International Management in 1987 from Social Sciences Institute of Istanbul University. She has published extensively in the field of Management and Organization, Human Resource Management, Project Management, Healthcare Management, Social Responsibility and Ethics, Logistics and Green Management, Crisis and Risk Management, Decision Making. She is the author of numerous scientific publications.

Ebru TURANOGLU BEKAR is currently the research assistant at İzmir University in Department of Industrial Engineering. She was a research assistant at Selcuk University from 2010 to 2012. Her research interests are Artificial Neural Network, Engineering Statistics, Forecasting, Fuzzy Sets Theory, Mathematical Programming, Multi-Criteria Decision Making, and Statistical Quality Control. She attends her PhD degree in Industrial Engineering at Dokuz Eylul University. She received her MSc degree in Industrial Engineering at Istanbul Technical University and Selcuk University in 2012. 